\title{
Pengelolaan Tanaman Tebu (Saccharum officinarum L.) di Wilayah PG Madukismo dengan Aspek Korelasi Pemupukan terhadap Produktivitas
}

\section{Management of Sugarcane Plant (Saccharum officinarum L.) in PG Madukismo Area by Aspect Correlation of fertilization on Productivity.}

\author{
Frans Paul Pakpahan dan Purwono* \\ Departemen Agronomi dan Hortikultura, Fakultas Pertanian, Institut Pertanian Bogor \\ (Bogor Agricultural University), Jalan Meranti, Kampus IPB Darmaga, Bogor 16680, Indonesia \\ Telp.\& Faks. 0251-8629353 e-mail : agronipb@indo.net.id \\ *Penulis untuk korespondensi : purwono@yahoo.com
}

Disetujui 20 Agustus 2018 / Published online 3 September 2018

\begin{abstract}
The low sugar production in Indonesia is mainly due to decreasing of productivity and low sugar yield. The effort to increase productivity is improving sugarcane cultivation techniques. One of the cultivation techniques releated to sugarcane productivity is fertilization. The intership is held from 06 February 2017 until 05 June 2017 in the working area of the Madukismo Sugar Factory,The Madubaru Company, Yogyakarta. This research was specifically aimed to examine the correlation of fertilization with sugarcane productivity. The result of observation indicate the correlation between fertilization and sugarcane productivity especially on ZA fertilizer. The addition of ZA fertilizer will increase sugarcane productivity where ZA fertilizer contains high $N$ content compared to other fertilizer so that can produce high cane yield. Increased productivity with the addition of ZA fertilizer was not followed by the sugar content. The sugar content is not significantly correlated with fertilization.
\end{abstract}

Keywords: productivity, farmers, fertilizer, sugar content

\begin{abstract}
ABSTRAK
Rendahnya produksi gula di Indonesia disebabkan karena menurunnya produktivitas dan rendemen tanaman tebu. Salah satu upaya untuk meningkatkan produktivitas adalah memperbaiki teknik budidaya tanaman tebu. Salah satu teknik budidaya yang perlu diperbaiki dan berhubungan dengan produktivitas tebu adalah pemupukan. Kegiatan penelitian dilaksanakan mulai 05 Februari 2017 hingga 05 juni 2017 di wilayah kerja PG Madukismo, Yogyakarta. Kegiatan penelitian ini secara khusus bertujuan untuk mengkaji korelasi pemupukan dengan produktivitas tanaman tebu. Hasil pengamatan menunjukkan adanya korelasi nyata antara pemupukan dengan produktivitas tanaman tebu terutama pada pupuk ZA. Penambahan pupuk $\mathrm{ZA}$ akan meningkatkan produktivitas tebu dimana pupuk ZA mengandung kandungan $\mathrm{N}$ yang tinggi dibandingkan dengan pupuk yang lain sehingga dapat menghasilkan bobot yang tinggi. Peningkatan produktivitas dengan penambahan pupuk ZA tidak diikuti dengan rendemen tebu yang dihasilkan. Rendemen tebu yang dihasilkan tidak berkorelasi nyata terhadap pemupukan.
\end{abstract}

Kata kunci : produktivitas, petani, pupuk, rendemen 


\section{PENDAHULUAN}

Tebu ( Saccarum officinarum L.) merupakan tanaman perkebunan yang memiliki peran stategis dalam perekonomian negara, yaitu dapat menghasilkan gula dan membutuhkan perhatian terus menerus dari pemerintah Perkembangan produksi tebu di Indonesia selama lima tahun terakhir terlihat cukup fluktuatif. Produksi Tebu tahun 2012 sebesar 2,59 juta ton, pada tahun 2013 mengalami penurunan mencapai 2,55 juta ton dan mengalami kenaikan sebesar 0,86 persen pada tahun 2014 menjadi sebesar 2,58 juta ton. Sementara tahun 2015 produksi tebu mengalami penurunan sebesar 1,57 persen atau menjadi 2,53 juta ton ( BPS, 2016). Pada tahun 2016 mengalami penurunan yang cukup jauh yaitu mencapai 2,20 juta ton (Ditjenbun,2017).

Produksi gula nasional saat ini bersumber dari 3 jenis status pengusahaan yaitu Perkebunan Rakyat

(PR), Perkebunan Besar Negara (PBN), dan Perkebunan Besar Swasta (PBS). Data luas areal pengusahaan tebu Indonesia menurut Statistik Perkebunan yang dikeluarkan Ditjen. Perkebunan Tahun 2014 menunjukan angka 478.108 ha, dari luasan tersebut Perkebunan Rakyat menguasai 290.967 ha atau sekitar 60,86\%, Perkebunan Besar Negara seluas 77.504 ha atau sekitar $16,21 \%$ dan Perkebunan Besar Swasta seluas 109.638 ha atau sekitar $22,93 \%$. Hal ini menunjukkan bahwa peran perkebunan tebu rakyat sangat menentukan keberhasilan program swasembada gula nasional (Ditjenbun, 2013).

Besarnya peran perkebunan rakyat pada keberadaan gula nasional membuat peran petani sangat berperan. Umumnya banyak petani tidak mengetahui teknik budidaya yang baik dalam tebu. Hal ini mengakibatkan keberagaman dalam hal teknik budidaya dimana salah satunya adalah pemupukan. Penggunaan pupuk sangatlah penting karena selain dapat membantu menyuburkan tanah juga dapat meningkatkan pertumbuhan dan perkembangan tanaman (Leiwakabessy dan Sutandi, 2004). Menurut Risza (2010), pemupukan merupakan proses penambahan tersedianya unsur hara dan perbaikan struktur tanah serta penggantian unsur-unsur hara yang hilang diserap atau diangkut oleh tanaman seperti yang tersimpan dalam tubuh tanaman, akibat penunasan, kastrasi, dan pemanenan buah. Hubungan jumlah pupuk yang digunakan akan berkaitan erat dengan tingkat produktivitas tanaman tebu (Indrawanto, 2010). Kegiatan penelitian ini bertujuan mempelajari dan mengkaji korelasi antara pemupukan dengan produktivitas tanaman tebu di wilayah kerja PG Madukismo PT Madubaru, Yogyakarta.

\section{METODE PENELITIAN}

Kegiatan penelitian dilaksanakan di wilayah PG Madukismo, Desa Tirtonimolo, Kasihan, Bantul, Yogyakarta selama 4 bulan mulai dari 5 Febuari sampai dengan 5 Juni 2017. Metode pelaksanaan kegiatan penelitian yang digunakan yaitu metode langsung dan tidak langsung. Metode langsung dilaksanakan dengan mengikuti kegiatan teknis di lapang. Metode tidak langsung adalah metode pengumpulan data tanpa mengikuti kegiatan teknis di lapang. Metode langsung yang dilaksanakan selama penelitian yaitu aspek khusus. Aspek khusus yang dilakukan yaitu mempelajari pemupukan di PG Madukismo. Data primer diperoleh dengan melakukan kegiatan, melakukan pengamatan, melakukan wawancara langsung dengan petani serta pengambilan data dari bagian gudang pupuk dan bagian tanaman serta melihat produktivitas tebu.

\section{Pengamatan, Pengumpulan Data dan Informasi}

Terdapat dua jenis data yang dikumpulkan yaitu data primer dan data sekunder. Data primer didapat ketika melakukan pengamatan langsung di lapang terhadap semua kegiatan yang berlangsung di kebun dan melakukan wawancara langsung dengan petani. Data primer yang didapat meliputi jenis pupuk yang digunakan, sumber pupuk, dosis pupuk yang digunakan, waktu pemupukan dan cara pemupukan. Selain itu pada taksisi tebu di bulan Mei akan melihat produktivitas tebu dengan berbagai indikator yaitu panjang batang, diameter batang, tinggi tanaman, berat kering tanaman per rumpun. Data akan diambil di bulan Maret dan April 2017 dari 4 blok kategori tanaman pada lahan sawah dan lahan tegalan. Setiap blok akan diambil 1 petak contoh. Setiap lahan akan diambil 10 tanaman contoh. Data primer diperoleh dari 2 wilayah yang berbeda dari setiap wilayah diambil 2 kebun contoh. Kebun contoh dilakukan taksasi Maret untuk mengetahui produktivitas tanaman tebu. Kegiatan wawancara dilakukan kepada petani sebanyak $10 \%$ dari jumlah petani di dua daerah kebun rakyat yang berbeda. Selain data primer, dilakukan juga pengumpulan data sekunder yang meliputi sejarah dan perkembangan perusahaan, letak geografis dan topografi, keadaan iklim, kondisi lahan, kondisi tanaman, organisasi dan manajemen perusahaan. Data sekunder yang dikumpulkan adalah data yang mendukung pelaksanaan teknis di lapangan, yang meliputi letak geografis kebun, kondisi iklim, kondisi lahan, 
kondisi areal dan tanaman, organisasi dan manajemen perusahaan serta tingkat produktivitas pabrik gula.

\section{Pengumpulan data Primer}

Data primer didapat dari hasil pengamatan. saat pengamatan yaitu :

\section{Wawancara Petani}

Setiap wilayah pengamatan dilakukan wawancara kepada petani (masing-masing 10\% dari satu wilayah) untuk mengetahui pemupukan yang dilakukan petani terhadap varietas tebu yang ditanam. Wawancara ini dilakukan dengan membagikan kuesioner kepada petani-petani di 2 kebun wilayah yang berbeda

\section{Taksasi Produksi}

Taksasi produsi dilakukan pada bulan maret selama 2 minggu. Kebun yang ditaksasi sebanyak 10 kebun untuk setiap wilayah pengamatan dan dilakukan bersama beberapa mandor dengan didampingi oleh sinder kebun wilayah. Parameter yang di amati yaitu
a) $\Sigma$ batang $\mathrm{m}^{-1}$, pengamatan dilakukan dengan melakukan perhitungan banyaknya batang per juring.

b) Bobot batang $\mathrm{m}^{-1}$, pengamatan bobot dilakukan dengan menebang batang tebu lalu ditimbang menggunakan alat penimbang sederhana, angka yang ada di timbangan merupakan hasil akhir bobot batang

c) Tinggi batang, pengamatan tinggi tanaman tebu diukur dari permukaan tanah atas guludan sampai daun +1 (titik patah). Batang yang diukur adalah batang tebu yang tumbuh normal dan tidak terserang hama dan penyakit.

d) $\Sigma$ juring $\mathrm{ha}^{-1}$, pengamatan jumlah juring dilakukan dengan menghitung banyaknya juring per ha.

e) $\mathrm{Pj}$ juring efektif, panjang juring yang memiliki tebu.

Produktivitas $=\Sigma$ batang $\mathrm{m}^{-1} \mathrm{X}$ Tinggi batang $\mathrm{X}$ Bobot batang $\mathrm{m}^{-1} \mathrm{X} \quad \Sigma$ juring ha $\mathrm{ha} \mathrm{Pj}^{-1} \mathrm{Puring}$ efektif.

\section{Pengukuran Brix}

Pengukuran brix dilakukan pada 5 batang tebu sehat berumur 8-10 bulan yang diambil secara silang. Batang tebu di potong menjadi 3 bagian (bagian bawah, tengah, dan atas) bila tidak dapat dipotong akan diberi tanda kepada 3 bagian dengan menggunakan spidol, kemudian di peras untuk diambil niranya dan diukur dengan menggunakan Brix handfractometer. Pengukuran dilakukan dimulai dari bagian atas. Angka yang keluar pada alat ini merupakan nilai brix yang sedang diamati.

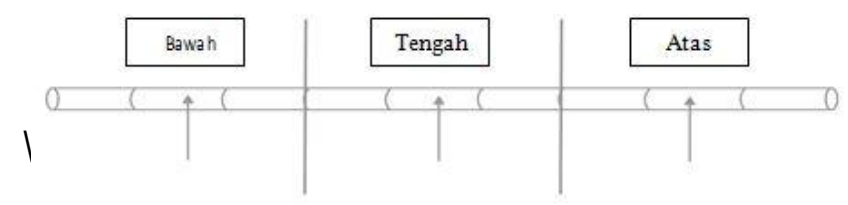

Gambar 1. Bagian yang diukur dengan Brix Handfractometer

Data dari kegiatan penelitian dianalisis dengan menggunakan perhitungan matematis sederhana yang meliputi nilai rata-rata dan persentase. Selain itu data dianalisis dengan menggunakan uji t-student dengan taraf 5\% dan dianalisis dengan korelasi sederhana menggunakan aplikasi minitab.

\section{HASIL DAN PEMBAHASAN}

Pengamatan dilakukan dengan melakukan wawancara petani tebu pada dua wilayah yaitu Bantul dan Purworejo dan melakukan taksasi pada kebun untuk melihat produktivitas yang akan dihasilkan Pemupukan pada tanaman tebu harus mengikuti azas enam tepat yaitu tepat waktu, jenis, jumlah, tempat, mutu, dan harga.

\section{Jenis Pupuk}

Jenis pemupukan pada petani di dua wilayah pengamatan umumnya sesuai dengan Rancangan Definitif Kebutuhan Definitif (RDKK) pupuk bersubsidi dimana menggunakan dua jenis pupuk yaitu pupuk organik dan pupuk anorganik. Pupuk organik yang digunakan adalah pupuk ZA dan pupuk NPK. Pupuk ZA mengandung unsur nitrogen $(\mathrm{N})$ sebanyak $21 \%$ dan unsur belerang (S) sebanyak $24 \%$. Selain pupuk ZA, tanaman tebu juga diberikan pupuk NPK dimana dengan perbandingan $15 \% \mathrm{~N}: 15 \% \quad \mathrm{P}_{2} \mathrm{O}_{5}: 15 \% \quad \mathrm{~K}_{2} \mathrm{O}$. Selain pupuk organik yang sesuai dengan RDKK, beberapa petani untuk wilayah pengamatan Purworejo menambahkan pupuk dasar berupa SP36 dimana mengandung $36 \% \mathrm{P}_{2} \mathrm{O}_{5}$.

\section{Dosis Pupuk}

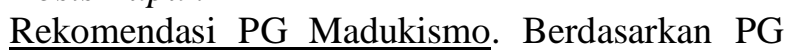
Madukismo, pemupukan pada jenis tanam plant cane adalah menggunakan Pupuk ZA sebanyak 5 $\mathrm{ku} \mathrm{ha-1}$, NPK sebanyak $5 \mathrm{ku} \mathrm{ha}^{-1}$, dan pupuk organik sebanyak $11 \mathrm{ku} \mathrm{ha}^{-1}$. Tanaman keprasaan atau ratoon cane dengan pupuk ZA dan NPK sebanyak masing-masing $5 \mathrm{ku} \mathrm{ha}^{-1}$. (Tabel 1). 
Tabel 1. Rekomendasi Pupuk PG Maduksimo

\begin{tabular}{lcc}
\hline \multirow{2}{*}{ Jenis Pupuk } & \multicolumn{2}{c}{ Dosis Pupuk $\left(\mathrm{kg} \mathrm{ha}^{-1}\right)$} \\
\cline { 2 - 3 } & Plant Cane (PC) & Ratoon (RC) \\
\hline ZA & 500 & 500 \\
NPK & 500 & 500 \\
Organik & 1100 & - \\
\hline
\end{tabular}

Sumber : Bina Sarana Tani PG Madukismo (2017)

Rekomendasi RDKK Pupuk Bersubsidi

Petani tebu umumnya menggunakan pupuk yang bersudsidi yang disusun dalam Rencana Definitif Kebutuhan Kelompok (RDKK) pupuk bersubsidi. Pemerintah memberikan pupuk bersubsidi dengan tujuan untuk membantu petani untuk memenuhi kebutuhan pupuk yang tepat.

Tabel 2. Rekomendasi pemupukan berdasarkan RDKK Pupuk Bersubsidi

\begin{tabular}{lcc}
\hline \multirow{2}{*}{ Jenis Pupuk } & \multicolumn{2}{c}{ Dosis Pupuk $\left(\mathrm{kg} \mathrm{ha}^{-1}\right)$} \\
\cline { 2 - 3 } & Bantul & Purwerejo \\
\hline ZA & 600 & 600 \\
NPK & 400 & 400 \\
Organik & 500 & 500 \\
\hline
\end{tabular}

Sumber : Koperasi petani tebu rakyat (2017)

\section{Realisasi Pupuk Anorganik}

Berdasarkan hasil wawancara dengan petani, pupuk anorganik yang dikeluarkan petani sangat beragam, ada yang sesuai dengan RDKK, sesuai dengan dosis PG, dan menambahkan pupuk
Dosis rekomendasi berdasarkan RDKK berbeda dengan rekomendasi PG Madukismo. Dosis tersebut terdapat pupuk ZA sebanyak $6 \mathrm{ku} \mathrm{ha}^{-1}$, pupuk NPK sebanyak $4 \mathrm{ku} \mathrm{ha}{ }^{-1}$, dan pupuk organik sebanyak $5 \mathrm{ku} \mathrm{ha}^{-1}$. sendiri. Petani wilayah Bantul umumnya mengunakan pupuk anorganik yang sesuai dengan RDKK (Tabel 3). Sedangkan, wilayah Purworejo umumnya menambah sendiri pupuk anorganiknya sehingga melebihi RDKK (Tabel 4).

Tabel 3. Realisasi Pupuk Anorganik wilayah pengamatan Bantul

\begin{tabular}{clccc}
\hline \multirow{2}{*}{ No Kebun } & \multirow{2}{*}{ Luas lahan (ha) } & \multicolumn{2}{c}{ Jenis Pupuk (kg ha-1) } \\
\cline { 3 - 5 } & & 1,00 & 500 & NPK \\
2 & Lemah dadi & 0,50 & 600 & 600 \\
3 & Nawungan I & 0,70 & 600 & 600 \\
4 & Selopamioro & 1,00 & 600 & 400 \\
5 & Panggang & 0,50 & 600 & 400 \\
6 & Jambu & 1,20 & 800 & 400 \\
7 & Kajor & 1,00 & 800 & 400 \\
8 & Kedung Jati & 0,60 & 400 & 400 \\
9 & Nawungan II & 0,50 & 400 & 700 \\
10 & Timbulharjo & 1,10 & 800 & 400 \\
11 & Selarong & 1,00 & 600 & 400 \\
\hline
\end{tabular}

Sumber : Hasil wawancara petani wilayah pengamatan (2017)

Berdasarkan Tabel 3 dan 4, Petani kedua wilayah lebih banyak menambahkan pupuk ZA dibandingkan dengan NPK atau SP-36. Pupuk ZA mengandung $\mathrm{N}$ yang tinggi. Penambahan pupuk yang mengandung unsur hara nitrogen akan meningkatkan efisiensi penggunaan cahaya matahari oleh tanaman tebu sehingga terlihat juga pada peningkatan bobot kering batang tebu yang merupakan komponen utama produksi tebu (Wawan et al., 2013). Hal ini yang mengakibatkan banyak petani tebu wilayah pengamatan menambahkan pupuk yang mengandung unsur nitrogen yang tinggi untuk menambah bobot batang tebu yang akan mengakibatkan meningkatnya produksi tebu. Namun, peningkatan produktivitas tidak diikuti dengan rendemen yang ikut naik hal ini dikarenakan penambahan pemupukan yang mengandung unsur hara $\mathrm{N}$ yang berlebihan akan mengakibatkan rendemen turun . Rendemen tertinggi pada pengaplikasian dosis pupuk $\mathrm{N}$ sebesar $140 \mathrm{~kg} \mathrm{ha}^{-1}$ (Nurhayati et al, 2013). 


\section{Cara Pemupukan}

Petani kedua wilayah melakukan pemupukan dengan cara menebarkan pupuk dalam tiap rumpun atau lubang. Sistem menebar pupuk digunakan gengaman tangan petani sehingga akan menghasilkan jumlah yang berbeda tiap rumpun atau tidak tetap. Setelah pemupukan umumnya dilakukan penutupan tanah atau urug.

\section{Waktu Pemupukan}

Pemupukan pada kedua wilayah dilakukan dengan dua kali dengan waktu yang tepat. Petani wilayah Bantul umumnya melakukan pemupukan I pada bulan Desember dan pupuk II dilakukan dua bulan setelah pupuk I yaitu bulan Februari. Petani Wilayah Purworejo melakukan pemupukan I pada bulan November dan pemupukan II pada bulan januari. Tetapi, wilayah

Tabel 5. Produktivitas kebun pengamatan di Bantul
Purworejo Selatan melakukan pemupukan lebih cepat yaitu pemupukan I dilakukan bulan Juli dan pemupukan II dilakukan bulan September. Hal ini dilakukan karena wilayah kerja Purworejo Selatan mudah terserang uret.

\section{Produktivitas}

Pengamatan produktivitas dilakukan dengan melakukan kegiatan taksasi di kebun wilayah pengamatan. Taksasi pada wilayah pengamatan Purworejo dilaksanakan pada bulan April. Sedangkan, wilayah pengamatan di Bantul dilakukan taksasi pada bulan Maret. Perhitungan produktivitas dilakukan dengan rumus produktivitas $=\Sigma$ batang $\mathrm{m}^{-1} \mathrm{X}$ Tinggi batang $\mathrm{X}$ Bobot batang $X \quad \Sigma$ juring $\mathrm{ha}^{-1} \mathrm{X} \mathrm{Pj}$ juring efektif.

\begin{tabular}{clrccccc}
\hline No & Nama Kebun & $\begin{array}{c}\text { Sbatang } \\
\mathrm{m}^{-1}\end{array}$ & $\begin{array}{c}\text { Tinggi } \\
\text { batang }\end{array}$ & $\begin{array}{c}\text { Bobot } \\
\text { batang }\end{array}$ & $\begin{array}{c}\begin{array}{c}\text { juring } \\
\text { ha }^{-1}\end{array} \\
\begin{array}{c}\text { Pj juring } \\
\text { efektif }\end{array}\end{array}$ & $\begin{array}{c}\text { Produktivitas (ku } \\
\left.\text { ha }^{-1}\right)\end{array}$ \\
\hline 1 & Lemah dadi & 6,00 & 2,36 & 0,43 & 900 & 10 & 548 \\
2 & Nawungan I & 11,00 & 1,97 & 0,33 & 900 & 10 & 649 \\
3 & Selopamioro & 7,70 & 2,02 & 0,40 & 900 & 10 & 553 \\
4 & Panggang & 7,10 & 1,84 & 0,36 & 900 & 10 & 424 \\
5 & Nogosari & 7,00 & 2,23 & 0,33 & 900 & 10 & 460 \\
6 & Jambu & 7,70 & 1,83 & 0,53 & 900 & 10 & 672 \\
7 & Kajor & 7,00 & 1,78 & 0,47 & 900 & 10 & 530 \\
8 & Kedung Jati & 6,30 & 1,84 & 0,43 & 900 & 10 & 446 \\
9 & Nawungan II & 6,90 & 1,83 & 0,34 & 900 & 10 & 390 \\
10 & Timbulharjo & 7,50 & 2,12 & 0,41 & 900 & 10 & 592 \\
11 & Selarong & 7,50 & 2,19 & 0,37 & 900 & 10 & 550 \\
12 & Ngentak & 7,70 & 2,01 & 0,40 & 900 & 10 & 544 \\
\hline & Rata-rata & 7,45 & 2,00 & 0,40 & 900 & 10 & 531 \\
\hline
\end{tabular}

Sumber : Hasil wawancara petani wilayah pengamatan (2017)

Tabel 6. Produktivitas kebun pengamatan di Purworejo

\begin{tabular}{clcccccc}
\hline No & Nama Kebun & $\begin{array}{c}\begin{array}{c}\text { batang } \\
\mathrm{m}^{-1}\end{array} \\
\text { Katang }\end{array}$ & $\begin{array}{c}\text { Tinggi } \\
\text { batang }\end{array}$ & $\begin{array}{c}\text { Bjuring } \\
\text { ha }^{-1}\end{array}$ & $\begin{array}{c}\text { Pj juring } \\
\text { efektif }\end{array}$ & $\begin{array}{c}\text { Produktivitas } \\
\left(\mathrm{ku} \mathrm{ha}^{-1}\right)\end{array}$ \\
\hline 1 & Kesidan & 8,20 & 2,50 & 0,50 & 900 & 10 & 925 \\
2 & Bandungrejo & 8,70 & 2,66 & 0,44 & 900 & 10 & 921 \\
3 & Kentengrejo & 8,20 & 2,54 & 0,45 & 900 & 10 & 838 \\
4 & Nampurejo & 7,80 & 2,15 & 0,43 & 900 & 10 & 655 \\
5 & Wonosari & 7,90 & 2,65 & 0,48 & 900 & 10 & 902 \\
6 & Karangsari & 6,90 & 2,09 & 0,49 & 900 & 10 & 634 \\
7 & Ngiboran & 7,00 & 2,78 & 0,50 & 900 & 10 & 880 \\
8 & Ngentak & 7,40 & 2,46 & 0,44 & 900 & 10 & 730 \\
9 & Wonoroto & 7,70 & 2,33 & 0,47 & 900 & 10 & 753 \\
10 & Harjobinangun & 7,50 & 2,19 & 0,55 & 900 & 10 & 821 \\
11 & Ketawang & 7,50 & 2,03 & 0,47 & 900 & 10 & 641 \\
12 & Cengir & 7,00 & 2,48 & 0,47 & 900 & 10 & 736 \\
\hline & Rata-rata & 7,65 & 2,41 & 0,47 & 900 & 10 & 786 \\
\hline
\end{tabular}


Tabel 7. Hasil uji t-student produktivitas di dua wilayah pengamatan

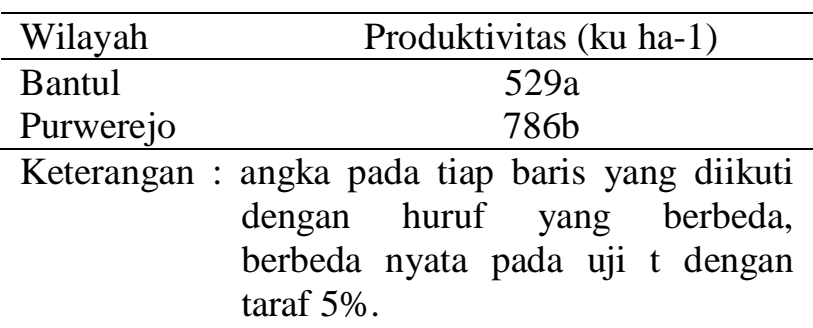

Berdasarkan Tabel 5 dan 6, Produktivitas kedua pengamatan cukup berbeda dimana wilayah Purworejo memiliki rata-rata sebesar $786 \mathrm{ku} \mathrm{ha}^{-1}$ lebih tinggi dibandingkan dengan wilayah Bantul yang hanya memiliki rata-rata produktivitas sebesar $529 \mathrm{ku} \mathrm{ha}^{-1}$. Terdapat perbedaan sekitar $257 \mathrm{ku} \mathrm{ha}^{-1}$. Jika dilakukan uji t, dapat dilihat produktivitas wilayah Purworejo berbeda nyata dengan wilayah bantul (Tabel 7). Hal ini disebabkan karena keadaan tanah yang berbeda pada kedua wilayah dan memiliki Bulan Basah (BB) yang berbeda. Wilayah Purworejo memiliki keadaan hujan yang lebih sedikit dibandingkan wilayah Bantul. Hal ini menyebabkan wilayah Bantul banyak memiliki ketersediaan air yang lebih banyak dibandingkan wilayah Purworejo. Ketersedian air sangat diperlukan untuk tanaman tebu pada fase vegetatif.

Tabel 8. Korelasi pemupukan wilayah pengamatan terhadap produktivitas

\begin{tabular}{|c|c|c|}
\hline \multirow{2}{*}{$\begin{array}{c}\text { Korelasi } \\
\text { Jenis Pupuk }\end{array}$} & \multicolumn{2}{|c|}{ Produktivitas (ku ha-1) } \\
\hline & Bantul & Purwerejo \\
\hline$\overline{Z A}$ & $0,638^{*}$ & $0,604 *$ \\
\hline NPK & 0,479 tn & $0,541 \mathrm{tn}$ \\
\hline SP-36 & - & $-0,362$ th \\
\hline Keterangan & $\begin{array}{l}*=\text { berkc } \\
0,05 ; \text { * }= \\
\text { nyata pada } \\
\text { berkorelasi } \mathrm{n}\end{array}$ & $\begin{array}{l}\text { nyata pada } \alpha \\
\text { gat berkorelasi } \\
1, \text { tn }=\text { tidak }\end{array}$ \\
\hline
\end{tabular}

\section{Korelasi Pemupukan terhadap Produktivitas}

Berdasarkan analisa korelasi, bahwa pada wilayah kedua pengamatan ada korelasi nyata antara pupuk ZA terhadap produktivitas tebu. Sedangkan Pupuk SP-36, NPK, berkorelasi tidak nyata terhadap produktivitas hasil. Hal ini disebabkan karena pupuk ZA mengandung unsur $\mathrm{N}$ yang lebih tinggi dibandingkan dengan NPK. Unsur hara $\mathrm{N}$ yang diserap tanaman tebu sangat tinggi sehingga mengakibatkan tanaman tebu menghasilkan produktivitas yang tinggi.

Tabel 9. Rata-rata brix lapangan kedua wilayah pengamatan

\begin{tabular}{lcccc}
\hline Wilayah & Atas & Tengah & Bawah & Rata-rata \\
\hline Bantul & 14,67 & 16,75 & 17,86 & $16,43 \mathrm{a}$ \\
Purworejo & 15,53 & 17,47 & 18,58 & $17,2 \mathrm{~b}$ \\
\hline
\end{tabular}

Keterangan : angka pada tiap baris yang diikuti dengan huruf yang berbeda, berbeda nyata pada uji t denga taraf $5 \%$.

Tabel 10. Hasil korelasi pemupukan terhadap brix lapangan kedua wilayah pengamatan

\begin{tabular}{lrc}
\hline Korelasi Jenis & \multicolumn{2}{c}{ Brix } \\
\cline { 2 - 3 } \multicolumn{1}{c}{ Pupuk } & Bantul & Purworejo \\
\hline ZA & 0,178 tn & 0,240 tn \\
NPK & 0,045 tn & $-0,349$ tn \\
SP-36 & - & 0,111 tn \\
\hline
\end{tabular}

Keterangan : * = berkorelasi nyata pada $\alpha 0,05$ ,** = sangat berkorelasi nyata pada $\alpha 0,01, \mathrm{tn}=$ tidak berkorelasi nyata

Menurut Nubatonis (2014), nilai brix pada lapangan merupakan salah satu faktor dalam penentu kebun untuk ditebang. Nilai brix lapangan akan berpengaruh terhadap rendemen. Standart brix yang layak untuk melakukan penebangan adalah 18. Berdasarkan tabel 9, rata-rata nilai brix kedua wilayah pengamatan masih dibawah standart yaitu untuk wilayah Bantul sebesar $16,43 \%$ dan untuk wilayah Purworejo hanya sebesar $17,2 \%$. Berdasarkan analisa korelasi, pemupukan tidak berkorelasi nyata pada $\alpha 0,05$ terhadap brix kedua wilayah. Hal ini dikarenakan tebu wilayah pengamatan menggunakan varietas Bululawang (BL) yang merupakan masak lambat sehingga kondisi tebu saat penebangan awal belum dalam kondisi tebu yang masak sehingga menghasilkan rendemen dan brix yang rendah. 
Tabel 11. Perbandingan analasi usaha tani dengan penggunaan pemupukan yang berbeda

\begin{tabular}{|c|c|c|c|c|c|}
\hline Uraian & Volume & Satuan & Harga satuan (Rp) & \multicolumn{2}{|c|}{ Harga (Rp) } \\
\hline Sewa lahan & - & - & - & & 8000000 \\
\hline Pengolahan lahan & - & - & - & & 2000000 \\
\hline $\mathrm{ZA}$ & 6 & $\mathrm{Ku}$ & & 140000 & 840000 \\
\hline NPK & 4 & $\mathrm{Ku}$ & & 230000 & 920000 \\
\hline Herbisida & - & - & - & & 300000 \\
\hline TK Penanaman/Kepras & - & - & - & & 700000 \\
\hline TK Urug + pupuk I & - & - & - & & 700000 \\
\hline TK Penyiangan + pupuk II & - & - & - & & 500000 \\
\hline TK Klentek & - & - & - & & 1200000 \\
\hline Tebang Angkut & 460 & $\mathrm{Ku}$ & & 5000 & 2300000 \\
\hline Total Pengeluaran & - & - & - & & 16660000 \\
\hline Produksi Tebu & 460 & $\mathrm{Ku}$ & - & & \\
\hline Rendemen Tebu & 6.05 & $\%$ & - & & \\
\hline Pendapatan Gula Petani & 2.245 & $\mathrm{Kg}$ & & 10000 & 22450000 \\
\hline Pendapatan tetes petani & 1380 & $\mathrm{Kg}$ & & 1200 & 1656000 \\
\hline Total Pendapatan & & & & & 24106000 \\
\hline Keuntungan & & & & & 7446000 \\
\hline Uraian & Volume & Satuan & Harga satuan (Rp) & Nilai & \\
\hline Sewa Lahan & - & - & $x_{2}$ & & 9000000 \\
\hline Pengolahan Lahan & - & - & - & & 1750000 \\
\hline Bibit & - & - & - & & 5000000 \\
\hline ZA & 8 & $\mathrm{Ku}$ & 140000 & & 980000 \\
\hline NPK & 7 & $\mathrm{Ku}$ & 230000 & & 1150000 \\
\hline Pupuk Kandang & 10 & $\mathrm{Ku}$ & 50000 & & 500000 \\
\hline Herbisida & - & - & - & & 500000 \\
\hline TK Penanaman/Kepras & - & - & - & & 700000 \\
\hline TK Urug + Pupuk I & - & - & - & & 700000 \\
\hline TK Penyiangan + Pupuk II & - & - & - & & 500000 \\
\hline TK Klentek & - & - & - & & 1500000 \\
\hline Tebak Angkut & 592 & $\mathrm{Ku}$ & 6000 & & 3552000 \\
\hline Total Pengeluaran & - & - & - & & 26682000 \\
\hline Produksi tebu & 592 & $\mathrm{Ku}$ & - & - & \\
\hline Rendemen tebu & 6.07 & $\%$ & - & - & \\
\hline Pendapatan gula petani & 3654 & $\mathrm{Kg}$ & 10000 & & 36540000 \\
\hline Pendapatan tetes petani & 1854 & $\mathrm{Kg}$ & 1200 & & 2224800 \\
\hline Total Pendapatan & & & & & 38764800 \\
\hline Keuntungan & & & & & 12082800 \\
\hline
\end{tabular}

Tabel 11 memperlihatkan bahwa adanya perbedaan pendapatan atau keuntungan yang digunakan petani pada satu wilayah kerja dengan perbandingan pemupukan yang diaplikasikan. Petani yang menggunakan pemupukan yang lebih besar menghasilkan produktivitas yang tinggi dan mendapatkan keuntungan yang cukup besar. Namun, penambahan pemupukan tidak berpengaruh nyata terhadap rendemen perbandingan hanya $0,02 \%$. Hal ini harus dicegah agar petani tidak hanya melihat dari sisi produktivitas saja tetapi harus memperhatikan rendemen gula juga karena untuk menjadikan gula diperlukan rendemen yang baik. Oleh karena itu, perlu kerja sama anatara perusahaan gula dan petani dalam membahas rendemen gula yang akan dihasilkan.

\section{KESIMPULAN}

Penggunaan pupuk pada petani tebu kedua pengamatan memiliki korelasi terhadap produktivitas tanaman tebu dimana berkorelasi nyata terhadap pupuk ZA, tetapi tidak berkorelasi nyata terhadap pupuk NPK dan KCL. Pupuk ZA mengandung hara nitrogen yang tinggi sehingga dapat meningkatkan bobot tebu yang tinggi pada hasil tebu sehingga dapat meningkatkan produktivitas tebu, Sehingga banyak petani yang mengaplikasikan pupuk ZA lebih banyak dibandingkan pupuk lainnya.

Korelasi pupuk ZA dan produktivitas tidak diikuti dengan nilai brix lapangan dan rendemen yang dihasilkan. Usaha tani dengan penambahan pemupukan yang melebihi RDKK menghasilkan keuntungan yang cukup besar. dicegah agar petani tidak hanya melihat dari sisi produktivitas saja tetapi harus memperhatikan rendemen gula. Keuntungan yang didapat hanya menguntungkan sebelah pihak yaitu pada pihak petani. Kerja sama antara pabrik gula dan petani sangat diperlukan dalam hal rendemen yang akan dihasilkan. 


\section{DAFTAR PUSTAKA}

[BPS] Badan Pusat Statistik. 2016. Perkembangan Produksi Tebu [Internet] [diunduh 2016 Agustus 24] Tersedia pada : http://www.bps.go.id/website/pdf_publika si/Statistik-Tebu-Indonesia-2015--.pdf

[Ditjenbun] Direktorat Jendral Perkebunan. 2013. Pengembangan Database Tebu Online [Internet] [diunduh 2016 April 25] Tersedia pada http://ditjenbun.pertanian.go.id/tansim/ber ita-267-pengembangan-database-tebuonline.html.

Indrawanto, C. 2010. Budidaya dan pasca panen tebu. ESKA Media. Jakarta.

Nurhayati, A. Basit, Sunawan. 2013. Hasil tebu keprasan pertama dan keprasan serta efesiensi penggunaan hara $\mathrm{N}$ dan $\mathrm{S}$ akibat substitusi ammonium sulfat. J. Agr. Indonesia 41 (1): 54-61.

Leiwakabessy, F.M., A. Sutandi. 2004. Pupuk dan Pemupukan. Jurusan Tanah. Fakultas Pertanian. Institut Pertanian Bogor. 207 hal.

Pembengo, W., Handoko., Suwarto. 2012. Efisiensi penggunaan cahaya matahari oleh tebu pada berbagai tingkat pemupukan nitrogen dan fosfor. J. Agr. Indonesia 40 (3):211-217.

Nubatonis, L.M. 2004. Kajian aplikasi teknologi membran pada proses pemurnian nira tebu [tesis]. Institut Pertanian Bogor. Bogor.

Risza, S. 2010. Masa Depan Perkebunan Kelapa Sawit Indonesia. Kasinisus. Yogyakarta 